\title{
NanoBRET ligand binding at a GPCR under endogenous promotion facilitated by CRISPR/Cas9
}

\section{genome editing}

Carl W White ${ }^{1,2,3 \#^{*}}$, Elizabeth K M Johnstone ${ }^{1,2,3 \#}$, Heng B See ${ }^{1,2,3}$ and Kevin D G Pfleger ${ }^{1,2,3,4 *}$

${ }^{1}$ Molecular Endocrinology and Pharmacology, Harry Perkins Institute of Medical Research, QEII Medical Centre, Nedlands, Western Australia 6009, Australia;

${ }^{2}$ Centre for Medical Research, The University of Western Australia, Crawley, Western Australia 6009, Australia;

${ }^{3}$ Australian Research Council Centre for Personalised Therapeutics Technologies, Australia;

${ }^{4}$ Dimerix Limited, Nedlands, Western Australia 6009, Australia

\# Authors contributed equally to this work

* Corresponding authors and persons to whom materials requests should be addressed:

Molecular Endocrinology and Pharmacology,

Harry Perkins Institute of Medical Research,

QEII Medical Centre,

6 Verdun Street,

Nedlands, Western Australia 6009, Australia

Phone: +618 61510734 


\begin{abstract}
Bioluminescence resonance energy transfer (BRET) is a versatile tool used to investigate membrane receptor signalling and function. We have recently developed a homogenous NanoBRET ligand binding assay to monitor interactions between $\mathrm{G}$ protein-coupled receptors and fluorescent ligands. However, this assay requires the exogenous expression of a receptor fused to the nanoluciferase (Nluc) and is thus not applicable to natively-expressed receptors. To overcome this limitation in HEK293 cells, we have utilised CRISPR/Cas9 genome engineering to insert Nluc in-frame with the endogenous ADORA2B locus this resulted in HEK293 cells expressing adenosine $A_{2 B}$ receptors under endogenous promotion tagged on their N-terminus with Nluc. As expected, we found relatively low levels of endogenous (geneedited) Nluc/ $\mathrm{A}_{2 \mathrm{~B}}$ receptor expression compared to cells transiently transfected with expression vectors coding for Nluc/ $\mathrm{A}_{2 \mathrm{~B}}$. However, in cells expressing gene-edited Nluc/ $\mathrm{A}_{2 \mathrm{~B}}$ receptors we observed clear saturable ligand binding of a non-specific fluorescent adenosine receptor antagonist XAC-X-BY630 $\left(K_{\mathrm{d}}=21.4 \mathrm{nM}\right)$. Additionally, at gene-edited Nluc/A $2 \mathrm{~B}$ receptors we derived pharmacological parameters of ligand binding; $K_{\mathrm{d}}$ as well as $K_{\mathrm{on}}$ and $K_{\text {off }}$ for binding of XAC-X-BY630 by NanoBRET association kinetic binding assays. Lastly, cells expressing gene-edited Nluc/ $\mathrm{A}_{2 \mathrm{~B}}$ were used to determine the $\mathrm{p} K_{\mathrm{i}}$ of unlabelled adenosine receptor ligands in competition ligand binding assays. Utilising CRISPR/Cas9 genome engineering here we show that NanoBRET ligand binding assays can be performed at geneedited receptors under endogenous promotion in live cells, therefore overcoming a fundamental limitation of NanoBRET ligand assays.
\end{abstract}

Key words: CRISPR/Cas9, fluorescent ligands, G protein-coupled receptor, methods, NanoBRET, ligand binding, Nluc

\footnotetext{
Abbreviations Clustered regularly interspaced short palindromic repeats (CRISPR), Nanoluciferase (Nluc), G protein-coupled receptor (GPCR), Bioluminescence resonance energy transfer (BRET), 5'(N-Ethylcarboxamido)adenosine (NECA), xanthine amine congener (XAC)
} 


\section{Introduction}

Bioluminescence resonance energy transfer (BRET) is the non-radiative transfer of energy between a bioluminescent donor and a fluorescent acceptor. One of the key requirements for energy transfer is the proximity between the donor and acceptor, with the efficacy of energy transfer being inversely proportional to the sixth power of the distance between donor and acceptor. This, in practice, limits the detection of proximity to $<10 \mathrm{~nm}^{1}$, thus providing a highly sensitive method to detect proximity between two tagged species in live cells and in real-time ${ }^{1,2}$. BRET assays can be readily configured in a variety of modes to investigate cellular signalling including many aspects of $\mathrm{G}$ protein-coupled receptor (GPCR) function, such as GPCR-protein interactions ${ }^{3,4}$, GPCR heteromerization ${ }^{5,6}$ G protein activation $^{7,8}$ and protein-protein interaction induced by GPCR activation ${ }^{9}$, as well as receptor internalization and trafficking ${ }^{10-12}$. Additionally, we and others have shown BRET can be multiplexed to investigate multiple interactions simultaneously ${ }^{13,14}$. Moreover, numerous BRET-based biosensors have also been developed ${ }^{15,16}$. Indeed, the wide range of applications of BRET technology has resulted in its extensive use in the field of GPCR pharmacology.

Recently we have developed a homogenous NanoBRET ligand binding assay to investigate binding of fluorescent ligands to $\mathrm{G}$ protein-coupled receptors ${ }^{17}$. This technique takes advantage of the discovery and subsequent engineering of the nanoluciferase (Nluc) from deep-sea shrimp Oplophorus gracilirostris. Nluc is a small $19 \mathrm{kD}$ luciferase that emits a bright, stable and spectrally narrow luminescence ${ }^{18}$, and has been used to observe binding of a fluorescent ligand to receptors with Nluc fused on their N-terminus. This method overcomes the safety and cost limitations of traditional radioligand binding methods, as well as the potential for high non-specific binding of fluorescent ligands due to partitioning into the lipophilic environments and/or uptake into the cell ${ }^{17}$. The assay also allows observation of ligand-receptor interactions at the population level in live cells, at $37^{\circ} \mathrm{C}$ and in real-time. The very high distance dependence of NanoBRET results in minimal non-specific binding, and due to the relative safety of the assay, the fluorescent probe can be used across many orders of magnitude of ligand concentration. Furthermore, the assay is truly homogenous with no wash or lysis step necessary, enabling kinetic measurements of ligand binding to be performed with relative ease which would be 
time-consuming and cumbersome in traditional radio-ligand binding studies. Indeed, due to its relative ease of use and adaptability, since the initial description of NanoBRET ligand binding, this method has been used in a variety of binding modes (saturation, kinetic or competition) to investigate fluorescent ligand binding at a number of GPCRs including: adenosine $\mathrm{A}_{1}$ and $\mathrm{A}_{3}$, as well as angiotensin II receptor type $1^{17} ; \beta_{1}$ and $\beta_{2}$-adrenoceptors ${ }^{17,19}$; free fatty acid receptors 1 and $2^{20,21}$; histamine $\mathrm{H}_{1}, \mathrm{H}_{3}$ and $\mathrm{H}_{4}$ receptors ${ }^{22,23}$; relaxin family peptide receptor $3^{24}$; and $\mathrm{P}_{2} \mathrm{Y}_{2}$ receptor ${ }^{25}$. It has also been used to study the receptor tyrosine kinase vascular endothelial growth factor $2^{26}$ and its co-receptor neuropilin- $1^{27}$.

Despite the advantages over traditional ligand binding methods using radio-ligands or fluorescent probes, a substantial limitation of this technique is that it requires the fusion of the donor luciferase to the receptor of interest. Therefore, unlike radio- and fluorescent-ligand binding, NanoBRET ligand binding has not been used at receptors expressed in cells under-endogenous promotion as the luciferase is lacking. Consequently, the assay requires exogenous expression of Nluc-tagged receptors, which can be routinely achieved by transient transfection of expression vectors but results in heterologous populations of cells with varying levels of over-expressed fusion protein. This needs to be considered as over-expression has the potential to alter protein function/localisation ${ }^{28}$. Other factors that can influence ligand interactions include the cellular environment in which a receptor is expressed and whether binding is measured in whole live cells or cell membrane preparations ${ }^{29}$. These potential limitations need to be considered when drawing conclusions from standard over-expression assays.

The discovery that the Cas9 nucleases can be harnessed for site-specific DNA cleavage in mammalian cells has been a major breakthrough in cellular biology ${ }^{30}$. Recently, we described the use of the CRISPR/Cas9 system to insert full-length Nluc into endogenous mammalian loci via homologydirected recombination ${ }^{13}$. Whilst engineering Nluc into the genome had been shown previously ${ }^{31}$, and fragments of Nluc have been engineered into the genome since ${ }^{32,33}$, we were able to demonstrate that receptors or proteins fused with Nluc on the C-terminus and expressed under endogenous promotion could be used in NanoBRET assays to monitor GPCR- $\beta$-arrestin interactions, GPCR internalisation and trafficking, as well as GPCR heteromerization ${ }^{6}$. Furthermore, these engineered cells could be used in multiplexed assays to investigate BRET between a donor and more than one acceptor simultaneously ${ }^{13}$. 
However, if the same technique could be used to tag receptors on the N-terminus with Nluc, which would be suitable for NanoBRET ligand binding assays, was not examined. Thus the aim of the current study was to investigate this possibility by targeting the adenosine $A_{2 B}$ receptor, which to our knowledge has not been used in NanoBRET ligand binding assays previously. Here, we show for the first time CRISPR/Cas9-mediated fusion of Nluc to the N-terminus of a GPCR and that binding of fluorescent ligand to these genome-edited Nluc/ $\mathrm{A}_{2 \mathrm{~B}}$ adenosine receptors can be observed by NanoBRET. Furthermore, we demonstrate that while these observations from gene-edited receptors are largely comparable to those from Nluc-tagged receptors that are over-expressed, they provide more consistent results when at similar levels of luminescence. Consequently, these results represent a timely advance to the NanoBRET ligand binding assay as model systems with more physiological relevance are being sought. 


\section{Methods:}

\subsection{Cell culture and transfection}

Wild type or CRISPR/Cas9-modified HEK293 cells were maintained at $37^{\circ} \mathrm{C}$ in $5 \% \mathrm{CO}_{2}$ and complete medium (Dulbecco's modified Eagle's medium (DMEM) containing $0.3 \mathrm{mg} / \mathrm{ml}$ glutamine, $100 \mathrm{IU} / \mathrm{ml}$ penicillin, $100 \mu \mathrm{g} / \mathrm{ml}$ streptomycin and $0.25 \mu \mathrm{g} / \mathrm{ml}$ amphotericin B (Thermo Fisher Scientific, Scoresby, VIC, Australia)) supplemented with $10 \%$ foetal bovine serum (FBS, Bovogen). Cells were transiently transfected according to the manufacturer's instructions using FuGENE 6 transfection reagent (Promega) with cDNA $24 \mathrm{~h}$ after seeding 500,000-550,000 cells/well in a 6-well plate. Cells were harvested with $0.05 \%$ Trypsin-EDTA (Thermo Fisher Scientific) and seeded into poly-L-lysine coated white 96-well plates at 50,000 cells/well in phenol red-free DMEM containing $25 \mathrm{mM}$ HEPES, 0.3 $\mathrm{mg} / \mathrm{ml}$ glutamine, $100 \mathrm{IU} / \mathrm{ml}$ penicillin and $100 \mu \mathrm{g} / \mathrm{ml}$ streptomycin supplemented with 5\% FBS, $24 \mathrm{~h}$ before performing an assay.

\subsection{Endpoint BRET assays}

After $24 \mathrm{~h}$ incubation, medium was removed from 96-well plates containing CRISPR/Cas9-modified or transiently transfected HEK293 cells. Saturation and competition ligand binding assays were performed by treating for 30 min with untagged competitor ligand and then adding fluorescent ligand and incubating for a further $60 \mathrm{~min}$. Ligand incubations were carried out at $37^{\circ} \mathrm{C}$ in $5 \% \mathrm{CO}_{2}$. Furimazine (Promega) was then added to a final concentration of $10 \mu \mathrm{M}$ and luminescence was measured immediately. BRET was measured at $37^{\circ} \mathrm{C}$ using the LUMIstar Omega microplate reader (BMG Labtech) using simultaneously-measured filtered light emissions at $450 \mathrm{~nm}$ ( $80 \mathrm{~nm}$ bandpass) and $>610$ $\mathrm{nm}$ (longpass). The raw BRET ratio was calculated by dividing the $>610 \mathrm{~nm}$ emission by the $450 \mathrm{~nm}$ emission.

\subsection{Kinetic BRET assays}

After $24 \mathrm{~h}$ incubation, medium was removed from 96-well plates containing CRISPR/Cas9-modified or transiently transfected HEK293 cells. Association kinetics ligand binding assays were performed by adding $10 \mu \mathrm{M}$ furimazine (Promega) and incubating at $37^{\circ} \mathrm{C}$ for $5 \mathrm{~min}$. Luminescence was then 
measured for $5 \mathrm{~min}$, reading every well once per minute. XAC-X-BY630 was then added to the required final concentration and luminescence measurements continued for a further 60 min. BRET was measured at $37^{\circ} \mathrm{C}$ using the LUMIstar Omega microplate reader (BMG Labtech) with simultaneouslymeasured filtered light emissions at $450 \mathrm{~nm}$ ( $80 \mathrm{~nm}$ bandpass) and >610 $\mathrm{nm}$ (longpass). The corrected BRET ratio was calculated by subtracting the vehicle-treated raw BRET ratio from the XAC-X-BY630treated raw BRET ratio, as described previously ${ }^{2}$.

\subsection{Luminescence assays}

After $24 \mathrm{~h}$ incubation, medium was removed from 96-well plates containing CRISPR/Cas9-modified, transiently transfected or wild type HEK293 cells. Immediately following addition of $10 \mu \mathrm{M}$ furimazine (Promega), luminescence was measured at $450 \mathrm{~nm}\left(80 \mathrm{~m}\right.$ bandpass) at $37^{\circ} \mathrm{C}$ using the LUMIstar Omega microplate reader (BMG Labtech).

\section{5 cAMP assays}

After $24 \mathrm{~h}$ incubation, medium was removed from 96-well plates containing CRISPR/Cas9-modified, transiently transfected or wild type HEK293 cells. cAMP accumulation was measured using a homogenous time-resolved fluorescence cAMP dynamic 2 assay kit (CisBio Bioassays) following the manufacturer's instructions. Briefly, cells were treated with NECA in stimulation buffer and incubated at $37^{\circ} \mathrm{C}$ in $5 \% \mathrm{CO}_{2}$ for $30 \mathrm{~min}$. Cells were then lysed by addition of assay reagents in lysis buffer. Plates were incubated for $1 \mathrm{~h}$ at room temperature and fluorescence was measured at $620 \mathrm{~nm}$ and $665 \mathrm{~nm}$, respectively, $50 \mathrm{~ms}$ after excitation at $337 \mathrm{~nm}$ using an EnVision 2102 microplate reader (PerkinElmer).

\subsection{Genome engineering}

HEK293 cells expressing genome-edited $\mathrm{A}_{2 \mathrm{~B}}$ receptor $\mathrm{N}$-terminally tagged with Nluc were generated by CRISPR/Cas9 mediated homology-directed repair as described previously ${ }^{13,34}$. The sgRNA sequence ccttcggtagggggegcccg was used for Cas9 targeting of the N-terminal region of ADORA2B. Templates for homology directed repair (Supplementary table 1) were synthesised by GeneArt (Thermo Fisher Scientific). Plasmids or genomic DNA sequences amplified by PCR (see supplementary table 2 for 
primers) were verified by Sanger sequencing by the Australian Genome Research Facility (Perth, Australia) using the method described previously ${ }^{13}$.

\section{7 cDNA constructs and ligands}

$\mathrm{A}_{2 \mathrm{~B}}$ receptor cDNA was obtained from Missouri S\&T cDNA Resource Center (www.cdna.org) in a pcDNA3 expression vector. pcDNA3.Nluc (no stop codon) was synthesised by GeneArt (Thermo Fisher Scientific) and encodes a fusion of the secretory signal peptide sequence of IL6 on the Nterminus of Nluc. Nluc/A ${ }_{2 B}$ receptor cDNA was generated by inserting the IL6 signal peptide/Nluc cDNA in-frame before the $\mathrm{A}_{2 \mathrm{~B}}$ receptor ORF. Adenosine, Angiotensin II (AngII) and XAC-X-BY630 (CA200634) were from Sigma. 5'-(N-Ethylcarboxamido)adenosine (NECA) was from Abcam. PSB 603, SCH 442416 and xanthine amine congener (XAC) were from Tocris. TAMRA-Angiotensin II (TAMRA-AngII) was from AnaSpec. ABEA-X-BY630 (CA200623) was from Hello Bio.

\subsection{Data presentation and statistical analysis}

Data were analysed using GraphPad Prism 7, as described previously ${ }^{17}$. Briefly, saturation ligand binding curves were generated using non-linear regression assuming one site binding, simultaneously fitting both total and non-specific binding (with the exception of SCH 442416 which was fitted as total binding). Competition ligand binding data and concentration-response data were fitted with sigmoidal curves generated using non-linear regression assuming one site binding. Competition ligand binding data were plotted as \% maximum BRET observed in the absence of unlabelled ligand with zero unconstrained. The baseline response, or full displacement of the fluorescent ligand, is therefore approximately $40 \%$ of maximum. Where appropriate, to calculate the $K_{\mathrm{i}}$ of the unlabelled ligands competition binding curves were fitted using the Cheng-Prusoff equation. Association kinetic data were analysed with global fitting of the different ligand concentrations, using non-linear regression. Statistical analysis was performed using GraphPad Prism 7 using a one-way ANOVA and where appropriate a multiple comparisons test. For comparisons between gene-edited and over-expressed Nluc/ $A_{2 B}$ receptors, statistical analysis was performed on paired data of three individual repeats. 
Otherwise comparisons were made using the individual repeats indicated in the figure legends. $\mathrm{p}<0.05$ was considered significant. 


\section{Results}

To establish if NanoBRET could also be used to monitor ligand binding at GPCRs under endogenous promotion, we targeted the adenosine $\mathrm{A}_{2 \mathrm{~B}}$ receptor, encoded by the ADORA2B gene. Preliminary examination of available expression data sets ${ }^{35}$ and literature ${ }^{36}$ indicated relatively low levels of endogenous expression in HEK293 cells, although at levels sufficient to generate a functional response following ligand stimulation ${ }^{37}$. Additionally, well-validated fluorescent adenosine receptor ligands are commercially available.

Using CRISPR/Cas9-mediated homology-directed DNA repair to append DNA coding for Nluc to the N-terminus of $A D O R A 2 B$ (Figure 1a), we engineered HEK293 cells to express Nluc/A $2 \mathrm{~B}$ under endogenous promotion. Cells obtained were heterozygous for the insert and in-frame insertion of the Nluc at the target genomic locus was confirmed via Sanger sequencing of genomic DNA (Supplementary figure 1a and b). Analysis of the luminescence generated by live cells (Figure 1b) showed only modest luminescence from cells expressing genome-edited Nluc/ $\mathrm{A}_{2 \mathrm{~B}}$ receptors, which corresponded to approximately $0.05 \mathrm{ng}$ of Nluc/ $\mathrm{A}_{2 \mathrm{~B}} \mathrm{cDNA}$ transfected transiently per well of a 6 well plate. Furthermore, using relative luminescence as a proxy for expression, the gene-edited Nluc/ $\mathrm{A}_{2 \mathrm{~B}}$ was expressed approximately 60 -fold lower than the gene-edited chemokine receptor CXCR4/Nluc that we generated previously ${ }^{13}$ in the same parental cell line (Supplementary figure 1c), indicating low levels of endogenous $\mathrm{A}_{2 \mathrm{~B}}$ receptor expression in HEK293 cells, even compared with other endogenously expressed GPCRs. Next, we investigated the effect of the genome editing process or fusion of Nluc onto the $\mathrm{N}$-terminus of the $\mathrm{A}_{2 \mathrm{~B}}$ receptor on receptor function. Consistent with our previous experience ${ }^{13}$, no differences in the potency of NECA-mediated cAMP accumulation were observed between cells expressing wild type $\mathrm{A}_{2 \mathrm{~B}}$, gene-edited Nluc/ $\mathrm{A}_{2 \mathrm{~B}}$ or over-expressed Nluc/ $\mathrm{A}_{2 \mathrm{~B}}$ receptors (Figure 1c, Table $1)$.

To test whether the levels of luminescence generated by gene-edited Nluc/A $\mathrm{A}_{2 \mathrm{~B}}$ under endogenous promotion were sufficient to observe ligand binding by NanoBRET (Figure 2a), we initially performed saturation binding experiments using increasing concentrations of the fluorescent adenosine receptor antagonist XAC-X-BY630. In live cells incubated at $37^{\circ} \mathrm{C}$, a saturable increase in BRET signal could 
clearly be observed and was completely inhibited in the presence of the $\mathrm{A}_{2 \mathrm{~B}}$-selective antagonist PSB 603 (Figure $2 \mathrm{~b}$ ). $K_{\mathrm{d}}$ values indicating the affinity of XAC-X-BY630 at gene-edited $\mathrm{A}_{2 \mathrm{~B}}$ receptors were calculated and were comparable to those obtained using cells transiently transfected with either $0.05 \mathrm{ng}$ or $5 \mathrm{ng}$ of cDNA encoding Nluc/A $\mathrm{A}_{2 \mathrm{~B}}$ per well of a 6 well plate (Table 1).

The very high spatial dependence of resonance energy transfer means the technique detects highly specific ligand binding, with very low levels of non-specific binding being observed. Our initial results using the $\mathrm{A}_{2 \mathrm{~B}}$-selective antagonist PSB $603\left(\mathrm{p} K_{\mathrm{i}}\right.$ of 9 versus $<5$ for other adenosine receptors $\left.{ }^{38}\right)$ in conjunction with XAC-X-BY630 would indicate that binding was exclusive to gene-edited Nluc/ $\mathrm{A}_{2 \mathrm{~B}}$. However, both $A_{2 A}$ and $A_{2 B}$ receptors have been reported to be expressed endogenously in HEK293 cells ${ }^{35}$. Therefore, using the selective $\mathrm{A}_{2 \mathrm{~A}}$ receptor antagonist $\mathrm{SCH} 442416\left(\mathrm{p} K_{\mathrm{i}}\right.$ of 9 versus $<5$ for $\mathrm{A}_{2 \mathrm{~A}}$ and other adenosine receptors respectively ${ }^{39}$ ) we sought to confirm our initial observation that non- $\mathrm{A}_{2 \mathrm{~B}}$ receptors were not contributing to the increase in BRET due to binding of XAC-X-BY630. As expected, no inhibition was observed at $1 \mu \mathrm{M} \mathrm{SCH} 442416$ (Figure 2c). However, to check if SCH 442416 could display the expected on-target $\mathrm{A}_{2 \mathrm{~B}}$ effects at high ligand concentrations, saturation binding in the presence of $10 \mu \mathrm{M} \mathrm{SCH} 442416$ (Figure 2d, p<0.05) was also performed. As expected, a small but significant inhibition of binding was observed that is consistent with $10 \mu \mathrm{M} \mathrm{SCH} 442416$ binding ontarget to Nluc/ $\mathrm{A}_{2 \mathrm{~B}}$ receptors, with these results also confirmed in our competition binding studies (Figure 3b). Next, we investigated if gene-edited Nluc/ $\mathrm{A}_{2 \mathrm{~B}}$ was acting as a donor sink at the plasma membrane that allowed for BRET to be observed in the presence of a fluorescent ligand as a consequence of bystander BRET. No specific binding was observed when cells expressing gene-edited Nluc/ $A_{2 B}$ were incubated with the unrelated fluorescent ligand TAMRA-AngII (Figure 2e). Finally, we tested if another fluorescent adenosine receptor ligand could bind gene-edited Nluc/ $\mathrm{A}_{2 \mathrm{~B}}$. For this purpose, we chose a fluorescent derivative of the adenosine agonist NECA, ABEA-X-BY630. While we noted a small increase in BRET that was blocked by $10 \mu \mathrm{M}$ PSB 603 (Figure 2f), in general a small window and variable binding was observed. It was therefore not possible to accurately determine the affinity of ABEA-X-BY630 via saturation ligand binding in our model. Low affinity interaction of this ligand with the $\mathrm{A}_{2 \mathrm{~B}}$ receptor is consistent with the literature ${ }^{40}$, however the relatively small increase in 
raw BRET could also indicate poor orientation between the donor and acceptor of the receptor-ligand pair, or possibly internalisation of the receptor contributing to the observed variability. Nevertheless, this indicates that NanoBRET binding to gene-edited Nluc/A $\mathrm{A}_{2 \mathrm{~B}}$ is not confined to XAC-X-BY630.

NanoBRET is a homogenous ligand binding assay, i.e. it doesn't require wash steps, and can be readily configured to investigate the kinetics of ligand binding. To further demonstrate that the gene-edited system can be used in the full range of NanoBRET ligand binding assays, we performed association kinetic experiments and determined the kinetic parameters, $K_{\mathrm{d}}$ values as well as $K_{\text {on }}$ and $K_{\text {off }}$, of XACX-BY630 binding at gene-edited $\mathrm{A}_{2 \mathrm{~B}}$ receptors (Figure 3a, Table 1), as well as in cells transiently transfected with $5 \mathrm{ng}$ cDNA coding for Nluc/A $2 \mathrm{~B}$ (Figure 4b). However, due to poor signal and global non-linear regression fitting, pharmacological parameters could not be determined from cells transiently transfected with $0.05 \mathrm{ng}$ cDNA coding for Nluc/ $\mathrm{A}_{2 \mathrm{~B}}$ (Figure 4e). In general, $K_{\mathrm{d}}$ values and kinetic parameters obtained were comparable between gene-edited and transiently expressed Nluc/ $\mathrm{A}_{2 \mathrm{~B}}$, as well as between saturation and kinetic binding experiments. However, small but statistically significant differences were observed for some comparisons (Table 1).

Finally, we investigated if NanoBRET ligand binding at gene-edited receptors can be used in competition binding assays to estimate the affinity of unlabelled adenosine receptor ligands. We tested a panel of 5 adenosine ligands and observed concentration-dependent decreases in the BRET signal, indicative of displacement of XAC-X-BY630, in the presence of XAC, PSB 603 and NECA (Figure $3 \mathrm{~b}$, Table 1). Adenosine and the $\mathrm{A}_{2 \mathrm{~A}}$-selective compound $\mathrm{SCH} 442416$ resulted in a decrease in the BRET signal but did not completely displace the fluorescent ligand at the concentrations used (Figure 3b). Similar results were observed in cells transiently transfected with cDNA coding for Nluc/ $A_{2 B}$ (Figure $4 \mathrm{c}$ and $\mathrm{f}$, Table 1) and are within the range reported in the literature ${ }^{41}$. Again, we observed greater noise and variation at the lower amount $(0.05 \mathrm{ng})$ of transiently transfected cDNA. 


\section{Discussion}

CRISPR/Cas9 genome engineering has revolutionised many aspects of cellular biology and this is just as true for GPCR pharmacology as other fields. Indeed, genome editing has found particular utility in probing the precise involvement of G proteins in GPCR-mediated cellular signalling via selective knockout of individual G protein subtypes ${ }^{42}$. However, potentially just as illuminating is the ability to insert a reporter tag into the genome via CRISPR/Cas9-mediated homology directed genome editing. This allows for the study of tagged receptors without the need to use over-expression vectors that have the potential to confound observations ${ }^{28}$. We have employed this strategy here to investigate fluorescent ligand binding at receptors under endogenous promotion with NanoBRET.

We targeted the adenosine $A_{2 B}$ receptor expressed in HEK293 cells for our experiments. As expected, we could readily engineer cells to express Nluc/ $\mathrm{A}_{2 \mathrm{~B}}$ receptors under endogenous promotion. Using luminescence as a proxy for receptor expression, we noted very low levels of endogenous adenosine $\mathrm{A}_{2 \mathrm{~B}}$ receptors in HEK293 cells. Indeed, to generate a comparable level of luminescence by transient transfection, only 0.05 ng DNA per well of a 6-well plate was required. As seen in Figure 4, due to the high background and levels of variability, transient transfection using this amount of cDNA is at the extreme lower range used in experiments and is not routinely used. This illustrates not only the exceptional sensitivity of NanoBRET ligand binding assays but also that endogenous levels of expression are difficult to replicate in transient expression models. Additionally, this demonstrates that we purposely did not select a highly expressed receptor for these proof-of-principle experiments and therefore the method should have wide applicability for other membrane receptors.

It is worth noting that while Nluc did not appear to affect the function of $A_{2 B}$ receptors expressed under endogenous promotion in HEK293 cells via cAMP signalling assays, the cells generated for these experiments were heterozygous for the insert. Therefore the presence of unedited wildtype receptor could mask any changes in function of the gene-edited receptor. However no change in NECA-mediated cAMP responses were observed when Nluc/ $\mathrm{A}_{2 \mathrm{~B}}$ receptors were over-expressed, indicating fusion of Nluc to the $\mathrm{N}$-terminus of $\mathrm{A}_{2 \mathrm{~B}}$ receptors is well tolerated. The focus of our experiments was to establish if NanoBRET ligand binding could be observed at receptors under endogenous promotion. Therefore, 
we did not examine in detail whether the engineering resulted in changes in endogenous receptor expression or receptor localisation, which may be altered due to the editing process or addition of Nluc. In our experience, Nluc does not normally cause mis-localisation, conceivably due to the stabilisation performed during the initial engineering of the native form of the luciferase ${ }^{18}$. However insertion of Nluc into the genome may also alter the rate of mRNA and/or $\mathrm{A}_{2 \mathrm{~B}}$ adenosine receptor synthesis and/or degradation, as well as their stability. Furthermore, genetic drift ${ }^{43}$ and/or signal pathway rewiring ${ }^{44}$ due to clonal isolation could have resulted in changes in Nluc/ $\mathrm{A}_{2 \mathrm{~B}}$ receptor expression compared to expression of wildtype receptor in the parental HEK293 cell lines. A further important consideration of using HEK293 cells is that they have a non-diploid karyotype and therefore generation of cells homozygous for the Nluc/A $\mathrm{A}_{2 \mathrm{~B}}$ fusion is a rare occurrence. As noted above, without the generation of homozygous clones, untagged $\mathrm{A}_{2 \mathrm{~B}}$ receptors would still be present, which, in addition to other endogenously expressed adenosine receptor subtypes, may provide additional sites for binding of the non-specific fluorescent ligand. $\mathrm{A}_{2 \mathrm{~B}}$-adenosine receptors are thought to form homo/hetero-oligomers ${ }^{45}$ and BRET is routinely used to investigate the close proximity of two tagged receptors albeit in exogenous overexpression models. Therefore we cannot rule out these sites contributing to an increase in BRET following application of the fluorescent ligand. However as discussed below, our data using the selective compound $\mathrm{SCH} 44241$ suggest we were not detecting binding to $\mathrm{A}_{2 \mathrm{~A}}$ adenosine receptors and due to the strong distance dependence of BRET it is highly unlikely that specific binding to these untagged $\mathrm{A}_{2 \mathrm{~B}}$ receptors would have been observed. Nevertheless, despite these caveats and exceptionally low levels of expression, we were able to observe clear reproducible fluorescent ligand binding via NanoBRET.

The utility of the NanoBRET ligand binding assay is the ability to determine pharmacological parameters of binding affinity in real-time, in live cells and at physiological temperatures. The affinities determined for the fluorescent probe XAC-X-BY630 at both gene-edited and over-expressed Nluc/ $\mathrm{A}_{2 \mathrm{~B}}$ receptors are within the range of those reported for the parental XAC compound ${ }^{41}$. Across the conditions tested (gene-edited as well as $0.05 \mathrm{ng}$ and $5 \mathrm{ng}$ over-expressed Nluc/ $\mathrm{A}_{2 \mathrm{~B}}$ ), binding affinities of labelled and unlabelled ligands were in general agreement, confirming the utility of both gene-edited and over- 
expressed assay configurations. For the $\mathrm{A}_{2 \mathrm{~B}}$ selective compound PSB 603, we noted across all assay configurations, a reduction in the BRET ratio generated by binding of XAC-X-BY630 even at the lowest concentration used (100 pM), as well as a lower binding affinity than initially reported. PSB 603 has been reported to act as an inverse agonist ${ }^{46}$ and to have allosteric properties ${ }^{47}$ that may be contributing to this effect. The initial report of sub-nanomolar affinity $(0.55 \mathrm{nM})$ of PSB 603 at $\mathrm{A}_{2 \mathrm{~B}}$ receptor used a radioactive $0.3 \mathrm{nM}\left[{ }^{3} \mathrm{H}\right] \mathrm{PSB} 603$ tracer in membrane preparations and also reported almost no displacement of radio-ligand traces from $\mathrm{A}_{1}, \mathrm{~A}_{2 \mathrm{~A}}$ and $\mathrm{A}_{3}$ receptors $\left(K_{\mathrm{d}}>10,000 \mathrm{nM}\right)^{38}$. However, in recent studies the affinity of PSB 603 was reported to be significantly lower $\left(K_{i} 1.89 \mathrm{nM}\right)$ when $30 \mathrm{nM}\left[{ }^{3} \mathrm{H}\right]$ NECA was used as the $\operatorname{tracer}^{48}$. Furthermore, the apparent dissociation equilibrium constant $\left(K_{\mathrm{B}}\right)$ of PSB 603 against a range of agonists was reported to be $3.6-66 \mathrm{nM}^{47}$. Combined, these reports indicate that differences in assay conditions and/or probe-dependence could explain the observations seen here. Indeed, in agreement with this, in whole cell competition binding assays, PSB 603 was observed to have much high affinity (pKi of 7.38 and 7.25) for $A_{1}$ and $A_{3}$ respectively than reported initially when a modified version of XAC-X-BY630 (CA200645) was used as the fluorescent probe $^{49}$. The extensive characterisation needed to fully delineate the causes of the PSB 603 observations and the small differences in binding affinity parameters found between assay configurations is currently hampered by the lack of additional fluorescent $\mathrm{A}_{2 \mathrm{~B}}$ adenosine receptor probes and was beyond the scope of our primary method development objective. Therefore, the possibility that either technical or intrinsic properties of the assay and/or ligands used are influencing the observations should be considered when interpreting the results.

NanoBRET ligand binding assays are possible only due to the development of fluorescent ligands. While these probes are used to investigate receptor binding via fluorescent microscopy, they can exhibit high levels of non-specific binding due to partitioning into lipophilic membrane environments or uptake into the cells. The high distance dependence of BRET overcomes this limitation, resulting in low levels of observable non-specific binding over a wide range of concentrations. Indeed, no binding was observed when we incubated cells with the unrelated fluorescent ligand TAMRA-AngII, confirming that bystander BRET has little effect in these assays. Additionally, we used the non-subtype-specific 
$\mathrm{XAC}$ fluorescent derivative and observed virtually no non-specific binding despite $\mathrm{A}_{2 \mathrm{~A}}$ receptors also being expressed endogenously in HEK293 cells $^{35,47}$. This is in contrast to traditional radio- or fluorescent-ligand binding assays where the use of non-subtype specific probes in systems expressing more than one target receptor requires extensive pharmacological characterisation and therefore highaffinity subtype selective probes are preferable. Furthermore, the use of CRISPR/Cas9 to generate cells expressing genome-edited Nluc-tagged receptors diminishes one of the few advantages that radio- and fluorescent-ligand binding have over resonance energy based binding techniques, as over-expression vectors are not required.

While significant advancement has been made in the availability of fluorescent ligands ${ }^{50}$, development of suitable fluorescent probes has the potential to limit the use of NanoBRET ligand binding. Therefore, the ability to use non-subtype-specific probes to investigate ligand binding in resonance energy binding assays is particularly useful and shifts the focus of specificity from the ligand to the receptor. Indeed, this allows for the use of a single fluorescent probe at multiple Nluc-tagged receptors, which is simpler to develop than the extensive medicinal chemistry required for the design of highly selective subtypespecific fluorescent ligands. This approach shows great promise in streamlining the development of fluorescent probes and has recently been elegantly exploited to investigate ligand binding by fluorescence resonance energy transfer assays where a non-specific probe was developed that bound 14 aminergic GPCRs with sub-nanomolar affinity ${ }^{51}$.

\section{Conclusions}

Here we present the first application of NanoBRET to monitor ligand binding at a GPCR under endogenous promotion in living cells. This combines the advantages of NanoBRET fluorescent ligand binding with the ability to investigate binding to non-overexpressed receptors. This advance is unlikely to be limited to GPCRs and should be applicable to investigate ligand binding by NanoBRET at other membrane proteins such as receptor tyrosine kinases. Additionally, the adaptability of gene-editing would allow targeted insertion of SNAP and/or Halotags required for lanthanide based time-resolved fluorescence resonance energy transfer-based binding assays. Our results represent a timely improvement in the NanoBRET ligand binding assay and, along with the progressive development of 
fluorescent ligands, the use of CRISPR/Cas9 genome engineering to generate Nluc-tagged receptors should facilitate efforts to investigate receptor function in models of greater physiological relevance. 
Acknowledgements This work was funded by a UWA Fellowship Support Grant to CWW and by ARC Linkage Grant LP160100857 to KDGP, as well as fellowship support from the National Health and Medical Research Council (NHMRC) of Australia to CWW (CJ Martin Research Fellowship, 1088334) and KDGP (RD Wright Biomedical Research Fellowship, 1085842).

Contributions CWW conceived the project. CWW and EKMJ designed experiments, analysed and interpreted the data. CWW, EKMJ and HBS performed the experiments. CWW and KDGP wrote and edited the manuscript. All authors approved of the final manuscript. Research materials are available on request.

Conflicts of Interest KDGP receives funding from Promega, BMG Labtech and Dimerix as Australian Research Council Linkage Grant participating organisations. These participating organisations played no role in any aspect of the conception or design of the research, collection, analysis and interpretation of results, or writing and editing of the manuscript. KDGP is Chief Scientific Advisor of Dimerix, of which he maintains a shareholding. CWW, EJ and HBS have nothing to disclose. 


\section{Figure Legends}

Figure 1: Design and validation of gene-edited adenosine $\mathbf{A}_{2 \mathrm{~B}}$ receptors. (a) Gene-editing strategy and features used to fuse Nluc onto the N-terminus of adenosine $A_{2 B}$ receptors expressed in HEK293 cells via CRISPR/Cas9 mediated homology-directed repair. (b) Comparison of luminescence generated by cells expressing genome-edited Nluc/ $\mathrm{A}_{2 \mathrm{~B}}$ (blue bars) or from cells transiently transfected with cDNA coding for Nluc/ $\mathrm{A}_{2 \mathrm{~B}}$ at $0.05,5$ or 0 ng per well of a 6-well plate (open, black and no [RLU 27] bar respectively). (c) cAMP accumulation mediated by NECA $(10 \mathrm{pM}-100 \mu \mathrm{M})$ in cells expressing genome-edited Nluc/ $\mathrm{A}_{2 \mathrm{~B}}$ (blue points) or in cells transiently transfected with cDNA coding for Nluc/ $\mathrm{A}_{2 \mathrm{~B}}$ at $0.05,5$ or 0 ng per well of a 6 -well plate (open squares, black circles and open triangles respectively). Points or bars represent mean \pm S.E.M. of three (c) or six (b) independent experiments.

Figure 2: Saturation NanoBRET ligand binding (a) at gene-edited Nluc/ $\mathbf{A}_{2 \mathrm{~B}}$ receptors. Cells expressing gene-edited Nluc/ $\mathrm{A}_{2 \mathrm{~B}}$ receptors were incubated with increasing concentrations of: $\mathrm{XAC}-\mathrm{X}$ BY630 (b-d) in the absence (black circles) and presence (red squares) of $10 \mu \mathrm{M}$ PSB 603 (b) or $1 \mu \mathrm{M}$ or $10 \mu \mathrm{M} \mathrm{SCH} 442416$ (c and d respectively, blue squares), (e) TAMRA-AngII in the absence and presence of $10 \mu \mathrm{M}$ AngII. (f) Cells were incubated without (white bar) or with $1.5 \mu \mathrm{M}$ ABEA-X-BY630 in the absence (red bar) and presence (black bar) of $10 \mu$ M PSB 603.. Saturation ligand binding curves were fitted as described in Methods with points representing the mean \pm S.E.M. of three (c-e), four (f) or six (b) independent experiments. ${ }^{* *}, \mathrm{p}<0.01$. 
Figure 3: Kinetic and competition ligand binding at gene-edited Nluc/ $\mathbf{A}_{2 \mathrm{~B}}$ receptors. (a) Cells expressing gene-edited Nluc/ $\mathrm{A}_{2 \mathrm{~B}}$ receptors were treated with 20, 40, 80 and $160 \mathrm{nM}$ XAC-X-BY630 (blue circles, open circles, red squares and closed black squares respectively) and BRET between Nluc and the fluorescent ligand was measured for 60 minutes. (b) Displacement of $30 \mathrm{nM}$ XAC-X-BY630 binding to gene-edited Nluc/A $\mathrm{A}_{2 \mathrm{~B}}$ by XAC (10 pM $-10 \mu \mathrm{M}$, black triangles), PSB 603 (100 pM - 100 $\mu \mathrm{M}$, blue diamonds), NECA (100 pM - $100 \mu \mathrm{M}$, open squares), SCH 442416 (100 pM - $100 \mu \mathrm{M}$, red circles) and adenosine (1 $\mathrm{nM}-1 \mathrm{mM}$, closed black circles). Corrected BRET ratio was calculated as described in Methods. (b) shows \% of maximum BRET observed for binding of $30 \mathrm{nM}$ XAC-X-BY630 in the presence of vehicle only. Kinetic and competition binding curves were fitted as described in Methods with points representing the mean \pm S.E.M. in (a) six and (b) six (SCH 442416), seven (adenosine, NECA and XAC) or ten (PSB 603) independent experiments.

Figure 4: NanoBRET ligand binding at over-expressed Nluc/ $\mathrm{A}_{2 \mathrm{~B}}$ receptors. Ligand binding in HEK293 cells transiently transfected with $0.05 \mathrm{ng}$ (a-c) or $5 \mathrm{ng}(\mathbf{d}-\mathbf{f})$ plasmid DNA coding for Nluc/A 2 в per well of a 6-well plate. (a and d) saturable ligand binding could be observed by incubating cells with increasing concentrations of XAC-X-BY630 in the absence (black circles) and presence (red squares) of $10 \mu \mathrm{M}$ PSB 603. (b and e) Kinetic ligand binding in cells transiently transfected with Nluc/A $\mathrm{A}_{2 \mathrm{~B}}$ receptors was observed by treatment of cells with 20, 40, 80 and $160 \mathrm{nM}$ XAC-X-BY630 (blue circles, open circles, red squares and closed black squares respectively) and monitoring BRET between Nluc and the fluorescent ligand for 60 minutes. (c and f) Displacement of $30 \mathrm{nM} \mathrm{XAC-X-BY630} \mathrm{binding} \mathrm{in}$ cells transiently transfected with Nluc/A $\mathrm{A}_{2 \mathrm{~B}}$ receptors by XAC $(10 \mathrm{pM}-10 \mu \mathrm{M}$, triangles $)$, PSB 603 (100 pM - $100 \mu \mathrm{M}$, blue diamonds), NECA (100 pM - $100 \mu \mathrm{M}$, open squares), SCH 442416 (100 pM - $100 \mu \mathrm{M}$, red circles) and adenosine ( $1 \mathrm{nM}-1 \mathrm{mM}$, closed black circles). Corrected BRET ratio was calculated as described in Methods. (c and f) plotted as \% of maximum BRET observed for binding of $30 \mathrm{nM}$ XAC-X-BY630 in the presence of vehicle only. Saturation, competition and kinetic curves were fitted as described in Methods with points representing the mean \pm S.E.M. of three independent experiments. 



\section{References:}

1 Pfleger, K. D. \& Eidne, K. A. Illuminating insights into protein-protein interactions using bioluminescence resonance energy transfer (BRET). Nat Methods 3, 165-174, doi:10.1038/nmeth841 (2006).

2 Pfleger, K. D., Seeber, R. M. \& Eidne, K. A. Bioluminescence resonance energy transfer (BRET) for the real-time detection of protein-protein interactions. Nat Protoc 1, 337-345, doi:10.1038/nprot.2006.52 (2006).

3 Hamdan, F. F., Audet, M., Garneau, P., Pelletier, J. \& Bouvier, M. High-throughput screening of $\mathrm{G}$ protein-coupled receptor antagonists using a bioluminescence resonance energy transfer 1-based beta-arrestin2 recruitment assay. J Biomol Screen 10, 463-475, doi:10.1177/1087057105275344 (2005).

4 Dalrymple, M. B., Jaeger, W. C., Eidne, K. A. \& Pfleger, K. D. Temporal profiling of orexin receptor-arrestin-ubiquitin complexes reveals differences between receptor subtypes. J Biol Chem 286, 16726-16733, doi:10.1074/jbc.M111.223537 (2011).

5 Mercier, J.-F., Salahpour, A., Angers, S., Breit, A. \& Bouvier, M. Quantitative Assessment of $\beta 1$ - and $\beta 2$-Adrenergic Receptor Homo- and Heterodimerization by Bioluminescence Resonance Energy Transfer. Journal of Biological Chemistry 277, 44925-44931, doi:10.1074/jbc.M205767200 (2002).

6 Mustafa, S. et al. Identification and Profiling of Novel $\alpha 1$ A-Adrenoceptor-CXC Chemokine Receptor 2 Heteromer. Journal of Biological Chemistry 287, 12952-12965, doi:10.1074/jbc.M111.322834 (2012). Ayoub, M. A., Trinquet, E., Pfleger, K. D. \& Pin, J. P. Differential association modes of the thrombin receptor PAR1 with Galphai1, Galpha12, and beta-arrestin 1. Faseb j 24, 35223535, doi:10.1096/fj.10-154997 (2010).

8 Gales, C. et al. Real-time monitoring of receptor and G-protein interactions in living cells. Nat Methods 2, 177-184, doi:10.1038/nmeth743 (2005).

9 Perroy, J., Pontier, S., Charest, P. G., Aubry, M. \& Bouvier, M. Real-time monitoring of ubiquitination in living cells by BRET. Nat Methods 1, 203-208, doi:10.1038/nmeth722 (2004).

10 Lan, T. H., Liu, Q., Li, C., Wu, G. \& Lambert, N. A. Sensitive and high resolution localization and tracking of membrane proteins in live cells with BRET. Traffic 13, 14501456, doi:10.1111/j.1600-0854.2012.01401.x (2012).

11 Tiulpakov, A. et al. Mutations of Vasopressin Receptor 2 Including Novel L312S Have Differential Effects on Trafficking. Mol Endocrinol 30, 889-904, doi:10.1210/me.2016-1002 (2016).

12 Lohse, M. J., Nuber, S. \& Hoffmann, C. Fluorescence/bioluminescence resonance energy transfer techniques to study G-protein-coupled receptor activation and signaling. Pharmacol Rev 64, 299-336, doi:10.1124/pr.110.004309 (2012).

13 White, C. W., Vanyai, H. K., See, H. B., Johnstone, E. K. M. \& Pfleger, K. D. G. Using nanoBRET and CRISPR/Cas9 to monitor proximity to a genome-edited protein in real-time. Sci Rep 7, 3187, doi:10.1038/s41598-017-03486-2 (2017).

14 Breton, B. et al. Multiplexing of multicolor bioluminescence resonance energy transfer. Biophys J 99, 4037-4046, doi:10.1016/j.bpj.2010.10.025 (2010).

15 Yano, H. et al. Development of novel biosensors to study receptor-mediated activation of the G-protein alpha subunits Gs and Golf. J Biol Chem 292, 19989-19998, doi:10.1074/jbc.M117.800698 (2017).

16 Charest, P. G., Terrillon, S. \& Bouvier, M. Monitoring agonist-promoted conformational changes of beta-arrestin in living cells by intramolecular BRET. EMBO Rep 6, 334-340, doi:10.1038/sj.embor.7400373 (2005).

17 Stoddart, L. A. et al. Application of BRET to monitor ligand binding to GPCRs. Nat Methods 12, 661-663, doi:10.1038/nmeth.3398 (2015). 
18 Hall, M. P. et al. Engineered luciferase reporter from a deep sea shrimp utilizing a novel imidazopyrazinone substrate. ACS Chem Biol 7, 1848-1857, doi:10.1021/cb3002478 (2012).

19 Soave, M., Stoddart, L. A., Brown, A., Woolard, J. \& Hill, S. J. Use of a new proximity assay (NanoBRET) to investigate the ligand-binding characteristics of three fluorescent ligands to the human $\beta 1$-adrenoceptor expressed in HEK-293 cells. Pharmacology Research \& Perspectives 4, e00250, doi:doi:10.1002/prp2.250 (2016).

20 Hansen, A. H. et al. Development and Characterization of a Fluorescent Tracer for the Free Fatty Acid Receptor 2 (FFA2/GPR43). Journal of Medicinal Chemistry 60, 5638-5645, doi:10.1021/acs.jmedchem.7b00338 (2017).

21 Christiansen, E., Hudson, B. D., Hansen, A. H., Milligan, G. \& Ulven, T. Development and Characterization of a Potent Free Fatty Acid Receptor 1 (FFA1) Fluorescent Tracer. Journal of Medicinal Chemistry 59, 4849-4858, doi:10.1021/acs.jmedchem.6b00202 (2016).

22 Stoddart, L. A. et al. Development of novel fluorescent histamine H1-receptor antagonists to study ligand-binding kinetics in living cells. Scientific Reports 8, 1572, doi:10.1038/s41598018-19714-2 (2018).

23 Mocking, T. A. M., Verweij, E. W. E., Vischer, H. F. \& Leurs, R. Homogeneous, Real-Time NanoBRET Binding Assays for the Histamine H3 and H4 Receptors on Living Cells. Mol Pharmacol 94, 1371-1381, doi:10.1124/mol.118.113373 (2018).

24 Wang, J.-H. et al. A novel BRET-based binding assay for interaction studies of relaxin family peptide receptor 3 with its ligands. Amino Acids 49, 895-903, doi:10.1007/s00726-017-2387-4 (2017).

25 Conroy, S. et al. Synthesis and Evaluation of the First Fluorescent Antagonists of the Human P2Y2 Receptor Based on AR-C118925. Journal of Medicinal Chemistry 61, 3089-3113, doi:10.1021/acs.jmedchem.8b00139 (2018).

26 Kilpatrick, L. E. et al. Real-time analysis of the binding of fluorescent VEGF165a to VEGFR2 in living cells: Effect of receptor tyrosine kinase inhibitors and fate of internalized agonist-receptor complexes. Biochem Pharmacol 136, 62-75, doi:10.1016/j.bcp.2017.04.006 (2017).

27 Peach, C. J. et al. Real-Time Ligand Binding of Fluorescent VEGF-A Isoforms that Discriminate between VEGFR2 and NRP1 in Living Cells. Cell Chemical Biology, doi:https://doi.org/10.1016/j.chembiol.2018.06.012 (2018).

28 Gibson, T. J., Seiler, M. \& Veitia, R. A. The transience of transient overexpression. Nat Methods 10, 715-721, doi:10.1038/nmeth.2534 (2013).

29 Vanderheyden, P. M. L. \& Benachour, N. Influence of the cellular environment on ligand binding kinetics at membrane-bound targets. Bioorg Med Chem Lett 27, 3621-3628, doi:10.1016/j.bmcl.2017.06.051 (2017).

30 Cong, L. et al. Multiplex genome engineering using CRISPR/Cas systems. Science 339, 819823, doi:10.1126/science.1231143 (2013).

31 Lackner, D. H. et al. A generic strategy for CRISPR-Cas9-mediated gene tagging. Nat Commun 6, 10237, doi:10.1038/ncomms10237 (2015).

32 Schwinn, M. K. et al. CRISPR-Mediated Tagging of Endogenous Proteins with a Luminescent Peptide. ACS Chem Biol 13, 467-474, doi:10.1021/acschembio.7b00549 (2018).

33 Oh-hashi, K., Furuta, E., Fujimura, K. \& Hirata, Y. Application of a novel HiBiT peptide tag for monitoring ATF4 protein expression in Neuro2a cells. Biochemistry and Biophysics Reports 12, 40-45, doi:https://doi.org/10.1016/j.bbrep.2017.08.002 (2017).

34 Ran, F. A. et al. Genome engineering using the CRISPR-Cas9 system. Nat Protoc 8, 22812308, doi:10.1038/nprot.2013.143 (2013).

35 Thul, P. J. et al. A subcellular map of the human proteome. Science 356, doi:10.1126/science.aal3321 (2017).

36 Atwood, B., Lopez, J., Wager-Miller, J., Mackie, K. \& Straiker, A. Expression of G proteincoupled receptors and related proteins in HEK293, AtT20, BV2, and N18 cell lines as revealed by microarray analysis. BMC Genomics 12, 1-14, doi:10.1186/1471-2164-12-14 (2011). 
37 Cooper, J., Hill, S. J. \& Alexander, S. P. H. An endogenous A(2B) adenosine receptor coupled to cyclic AMP generation in human embryonic kidney (HEK 293) cells. British Journal of Pharmacology 122, 546-550, doi:10.1038/sj.bjp.0701401 (1997).

38 Borrmann, T. et al. 1-alkyl-8-(piperazine-1-sulfonyl)phenylxanthines: development and characterization of adenosine $\mathrm{A} 2 \mathrm{~B}$ receptor antagonists and a new radioligand with subnanomolar affinity and subtype specificity. J Med Chem 52, 3994-4006, doi:10.1021/jm900413e (2009).

39 Todde, S. et al. Design, Radiosynthesis, and Biodistribution of a New Potent and Selective Ligand for in Vivo Imaging of the Adenosine A2A Receptor System Using Positron Emission Tomography. Journal of Medicinal Chemistry 43, 4359-4362, doi:10.1021/jm0009843 (2000).

40 Middleton, R. J. et al. New Fluorescent Adenosine A1-Receptor Agonists That Allow Quantification of Ligand-Receptor Interactions in Microdomains of Single Living Cells. Journal of Medicinal Chemistry 50, 782-793, doi:10.1021/jm061279i (2007).

41 Alexander, S. P. et al. THE CONCISE GUIDE TO PHARMACOLOGY 2017/18: G proteincoupled receptors. Br J Pharmacol 174 Suppl 1, S17-s129, doi:10.1111/bph.13878 (2017).

42 Milligan, G. \& Inoue, A. Genome Editing Provides New Insights into Receptor-Controlled Signalling Pathways. Trends in Pharmacological Sciences 39, 481-493, doi:10.1016/j.tips.2018.02.005 (2018).

43 Ben-David, U. et al. Genetic and transcriptional evolution alters cancer cell line drug response. Nature 560, 325-330, doi:10.1038/s41586-018-0409-3 (2018).

44 Luttrell, L. M. et al. Manifold roles of $\beta$-arrestins in GPCR signaling elucidated with siRNA and CRISPR/Cas9. Science Signaling 11, doi:10.1126/scisignal.aat7650 (2018).

45 Moriyama, K. \& Sitkovsky, M. V. Adenosine A2A receptor is involved in cell surface expression of A2B receptor. Journal of Biological Chemistry, doi:10.1074/jbc.M109.098293 (2010).

46 Vecchio, E. A. et al. Ligand-Independent Adenosine A $<$ sub $>2 \mathrm{~B}</$ sub $>$ Receptor Constitutive Activity as a Promoter of Prostate Cancer Cell Proliferation. Journal of Pharmacology and Experimental Therapeutics 357, 36-44, doi:10.1124/jpet.115.230003 (2016).

47 Goulding, J., May, L. T. \& Hill, S. J. Characterisation of endogenous A2A and A2B receptormediated cyclic AMP responses in HEK 293 cells using the GloSensor biosensor: Evidence for an allosteric mechanism of action for the A2B-selective antagonist PSB 603. Biochem Pharmacol 147, 55-66, doi:10.1016/j.bcp.2017.10.013 (2018).

48 Hinz, S., Alnouri, W. M., Pleiss, U. \& Muller, C. E. Tritium-labeled agonists as tools for studying adenosine A2B receptors. Purinergic Signal, doi:10.1007/s11302-018-9608-5 (2018).

49 Stoddart, Leigh A. et al. Fragment Screening at Adenosine-A3 Receptors in Living Cells Using a Fluorescence-Based Binding Assay. Chemistry \& Biology 19, 1105-1115, doi:http://dx.doi.org/10.1016/j.chembiol.2012.07.014 (2012).

50 Vernall, A. J., Hill, S. J. \& Kellam, B. The evolving small-molecule fluorescent-conjugate toolbox for Class A GPCRs. British Journal of Pharmacology 171, 1073-1084, doi:10.1111/bph.12265 (2014).

51 Hounsou, C. et al. From the Promiscuous Asenapine to Potent Fluorescent Ligands Acting at a Series of Aminergic G-Protein-Coupled Receptors. J Med Chem 61, 174-188, doi:10.1021/acs.jmedchem.7b01220 (2018). 
Figure 1

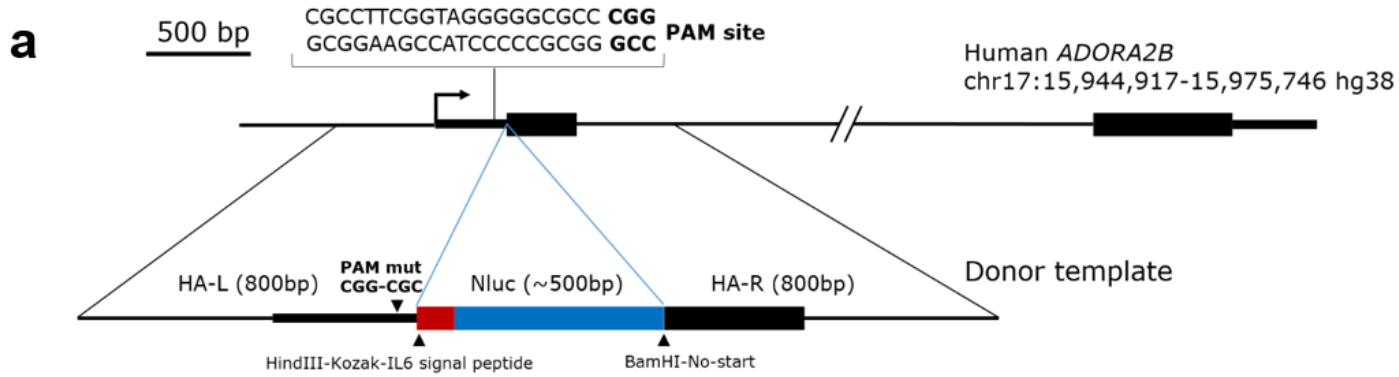

Fusion protein

b

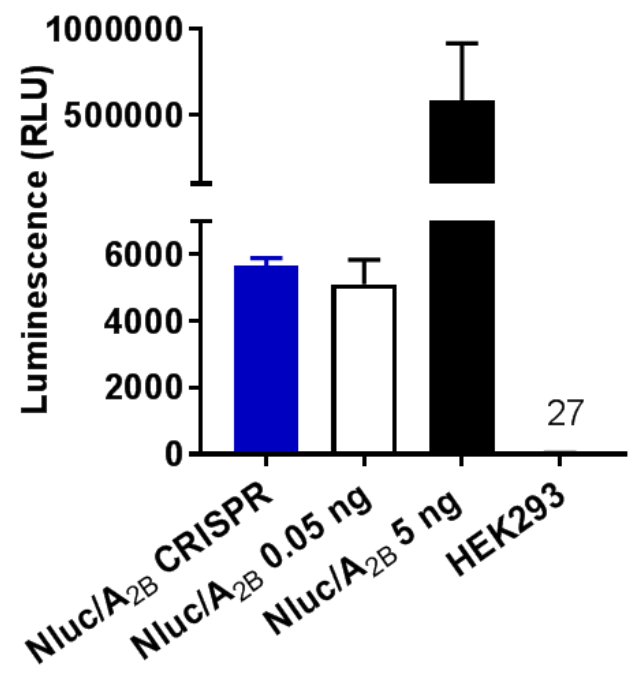

C

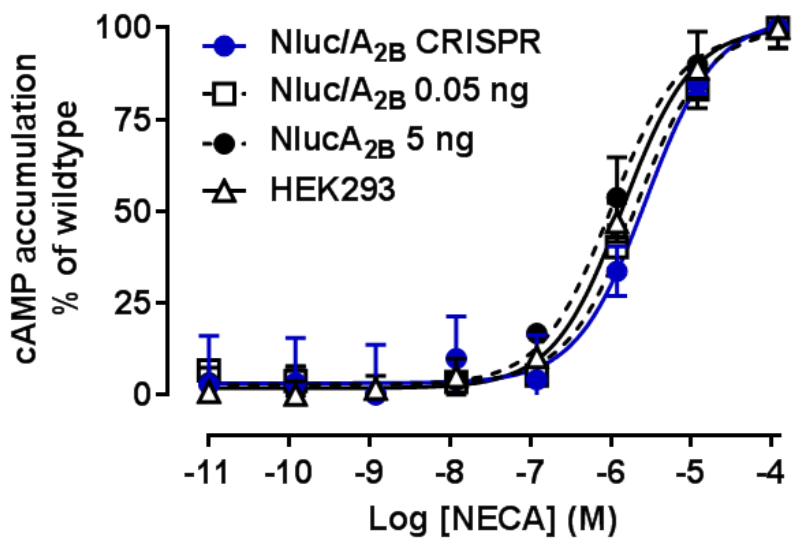


Figure 2
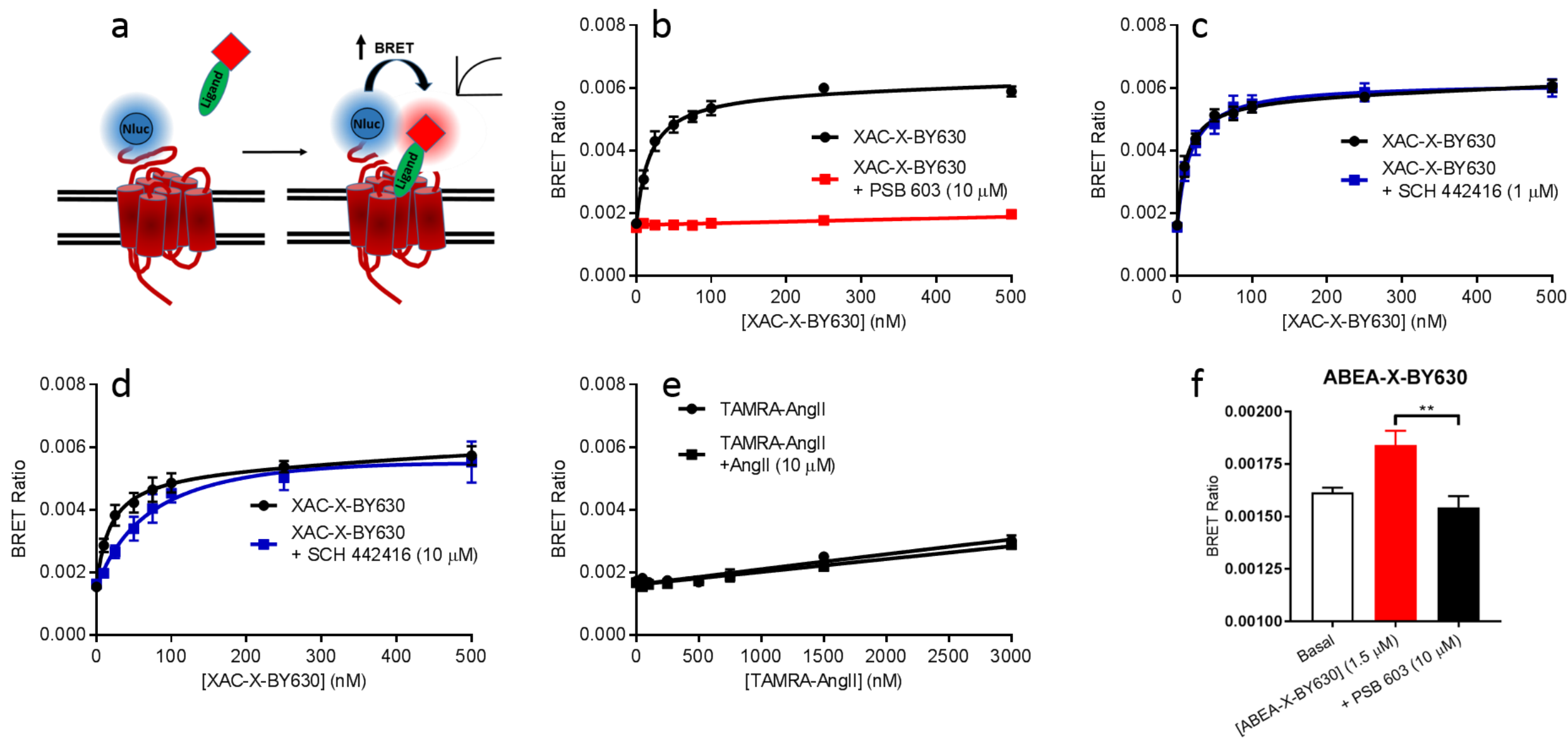
Figure 3
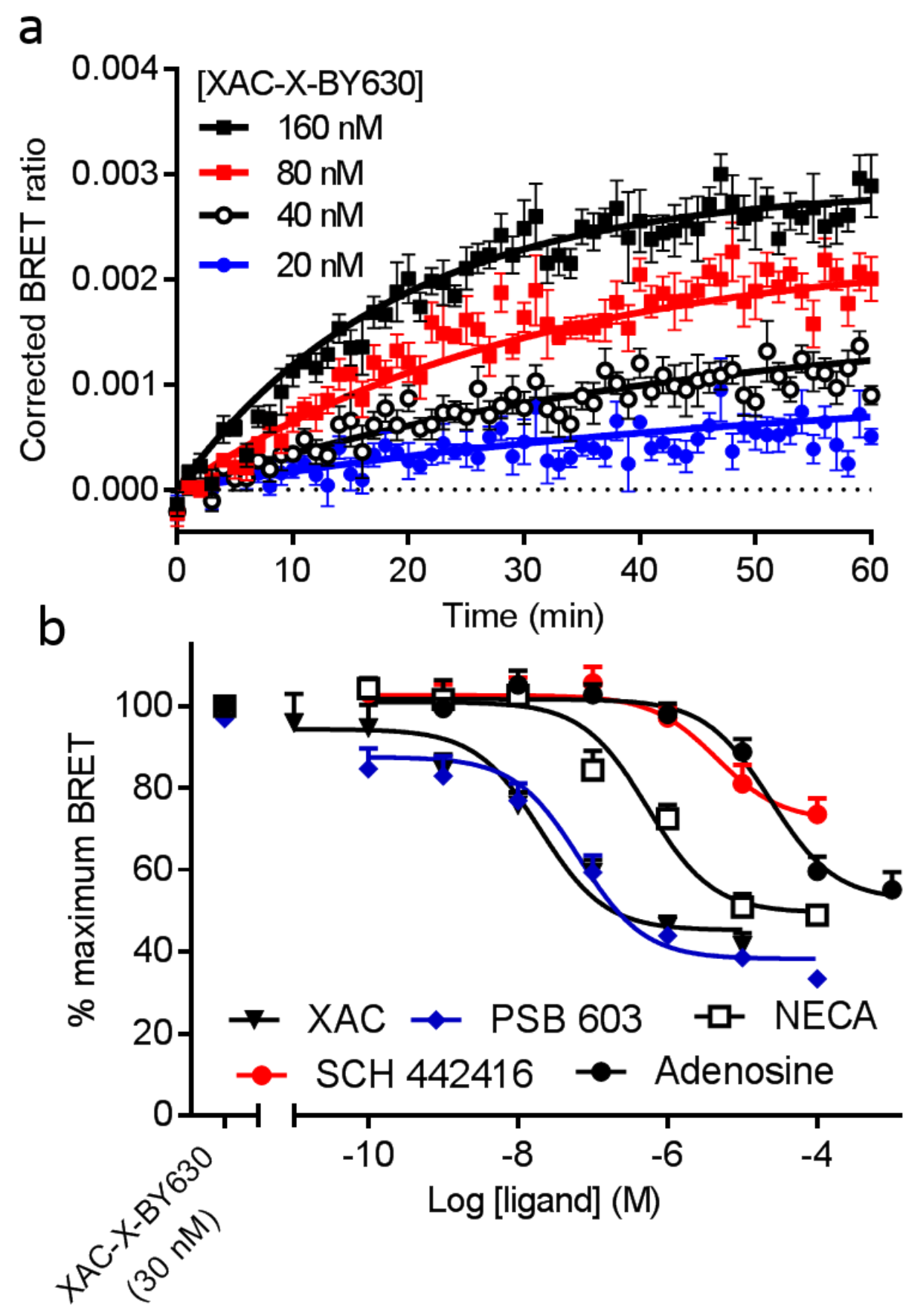
Figure 4
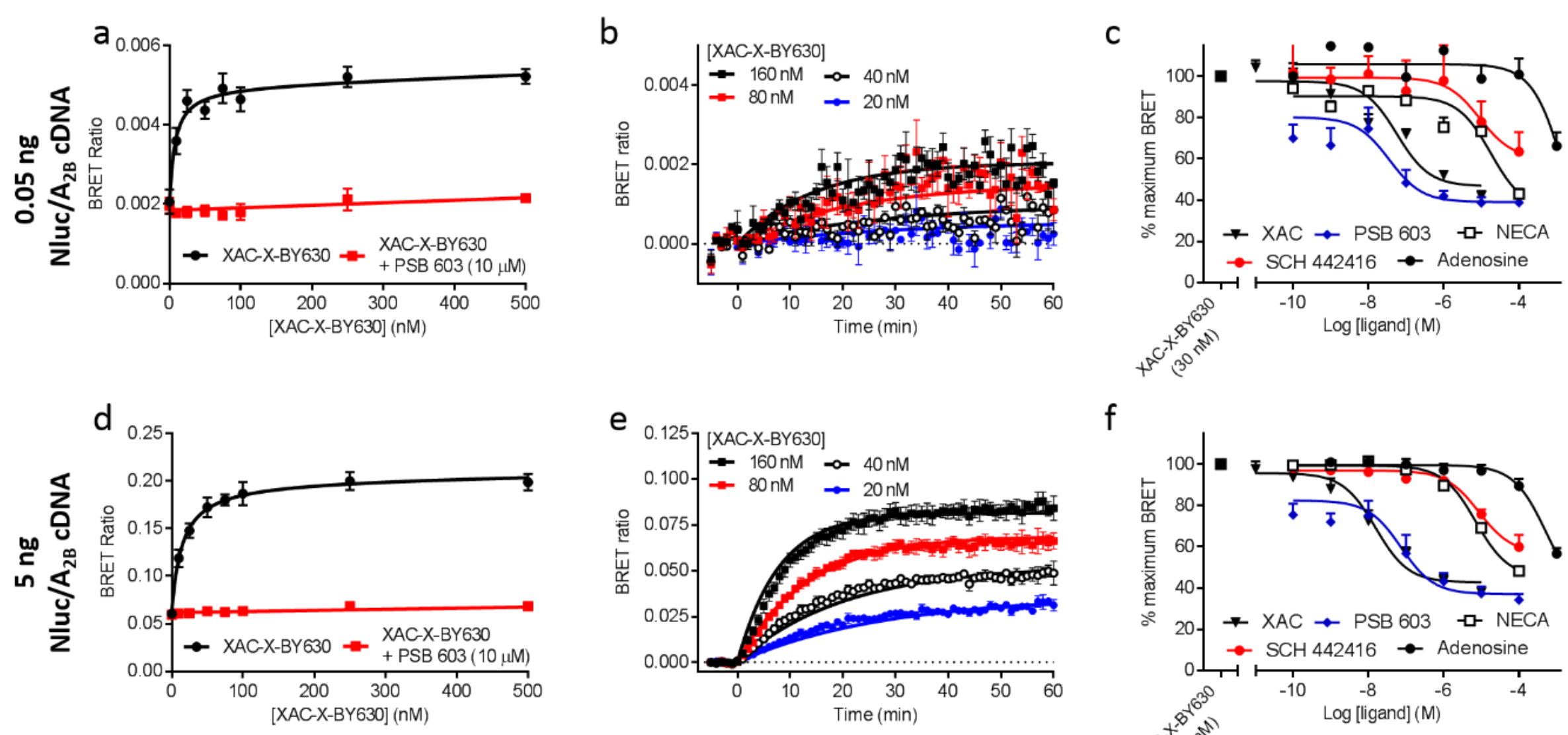

f

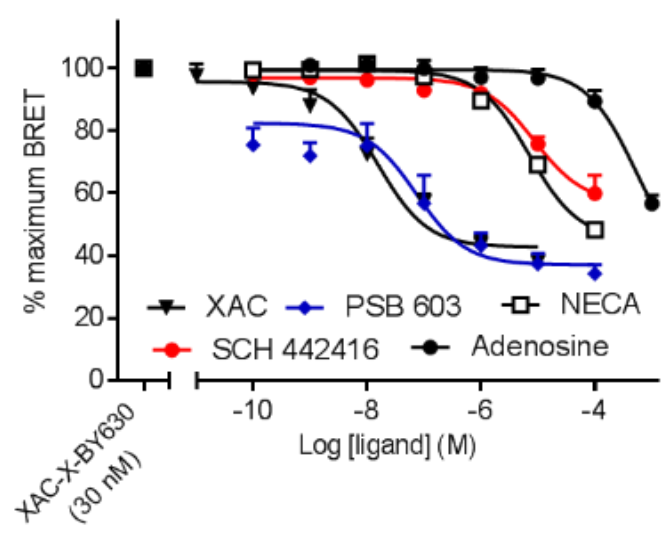


Table 1: Summary of pharmacological parameters calculated for ligand binding at $\mathrm{A}_{2 \mathrm{~B}}$ adenosine receptors in this study.

\begin{tabular}{|c|c|c|c|c|c|}
\hline Cell line & Nluc/A 2B $_{\text {B }}$ CRISPR & Nluc/A $A_{2 B} 0.05 \mathrm{ng}$ & Nluc/A ${ }_{2 B} 5 \mathrm{ng}$ & HEK293 wild type & Literature $\mathbf{p} K_{i}$ \\
\hline $\begin{array}{l}\text { NECA mediated cAMP } \\
\text { accumulation }\left(\mathrm{pEC}_{50}\right)\end{array}$ & $5.54 \pm 0.10$ & $5.68 \pm 0.10$ & $5.95 \pm 0.19$ & $5.84 \pm 0.10$ & \\
\hline Saturation $K_{d}(\mathrm{nM}, \mathrm{XAC}-\mathrm{X}-\mathrm{BY} 630)$ & $21.4 \pm 6.7 \#$ & $7.2 \pm 3.3$ & $14.8 \pm 1.8 \#$ & - & \\
\hline $\begin{array}{l}\text { Kinetic parameters (XAC-X- } \\
\text { BY630) }\end{array}$ & & & & - & \\
\hline$K_{\mathrm{on}}\left(\mathrm{M}^{-1} \min ^{-1}\right)$ & $2.70 \pm 0.86 \times 10^{5 *}$ & nd & $6.82 \pm 0.91 \times 10^{5 *}$ & - & \\
\hline$K_{\text {off }}\left(\min ^{-1}\right)$ & $0.016 \pm 0.003$ & nd & $0.024 \pm 0.007$ & - & \\
\hline Kinetic $K_{\mathrm{d}}(\mathrm{nM})$ & $88 \pm 23.5 \#$ & nd & $34.6 \pm 5.8 \#$ & - & \\
\hline \multicolumn{6}{|l|}{ Competition binding $\left(\mathrm{pK}_{\mathrm{i}}\right)$} \\
\hline XAC & $8.07 \pm 0.12$ & $8.47 \pm 0.46$ & $8.59 \pm 0.18$ & - & $6.9-8.8$ \\
\hline PSB 603 & $7.72 \pm 0.22$ & $8.68 \pm 0.78$ & $8.01 \pm 0.48$ & - & $8.7,9.3$ \\
\hline Adenosine & nd & nd & nd & - & $4.8-5.3$ \\
\hline NECA & $6.65 \pm 0.21$ & nd & nd & - & $5.7-6.9$ \\
\hline $\mathrm{SCH} 442416$ & nd & nd & nd & - & $<5.0$ \\
\hline
\end{tabular}

Values represent mean \pm S.E.M. with the number of individual repeats indicated in the relevant figure legends. For comparisons between gene-edited and over-expressed $\mathrm{Nluc} / \mathrm{A}_{2 \mathrm{~B}}$ receptors, statistical analysis performed on paired data of three individual repeats. \#, indicates a significant difference $(\mathrm{p}<0.05)$ between the $K_{\mathrm{d}}$ calculated for XAC-X-BY630 in the saturation and kinetic binding experiments. *, indicates a significant difference $(\mathrm{p}<0.05)$ between the $K_{\mathrm{on}}$ of XAC-X-BY630 in cells expressing gene-edited Nluc/ $\mathrm{A}_{2 \mathrm{~B}}$ or $5 \mathrm{ng}$ of transfected plasmid. $\mathrm{p} K_{\mathrm{i}}$ calculated using the Cheng-Prusoff equation as described in Methods using $30 \mathrm{nM}$ XAC-X-BY630. nd, not determined. $\mathrm{p} K_{\mathrm{i}}$ values from literature are from the IUPHAR/BPS Guide To PHARMACOLOGY ${ }^{41}$ and are against various probes. Values for PSB $603^{38,48}$ and $\mathrm{SCH} 442416^{39}$ where obtained using $\left.0.3 \mathrm{nM} \mathrm{[}{ }^{3} \mathrm{H}\right] \mathrm{PSB} 603,30 \mathrm{nM}\left[{ }^{3} \mathrm{H}\right]$ NECA or $34 \mathrm{nM}\left[{ }^{3} \mathrm{H}\right]$ DPCPX as the tracer respectively. 


\section{a}

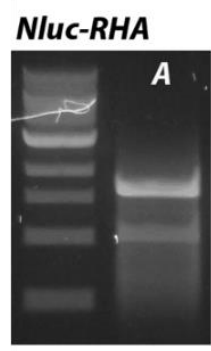

b
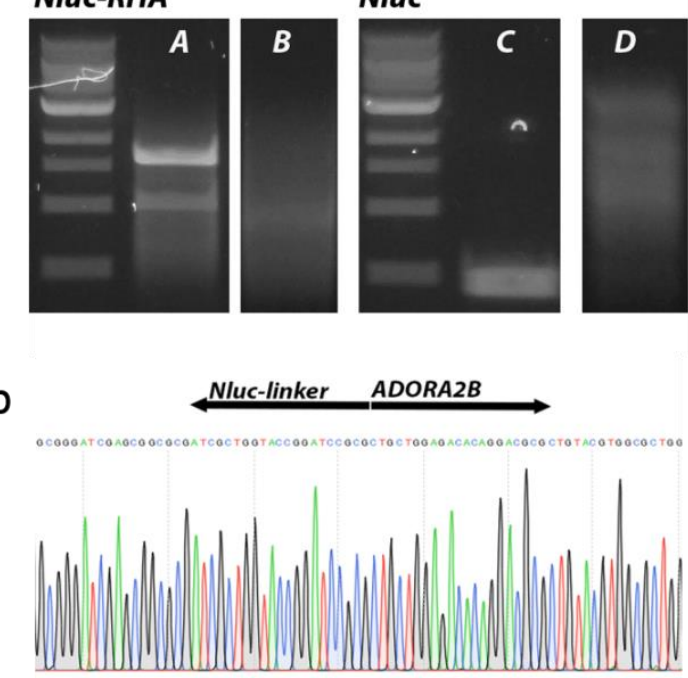

C

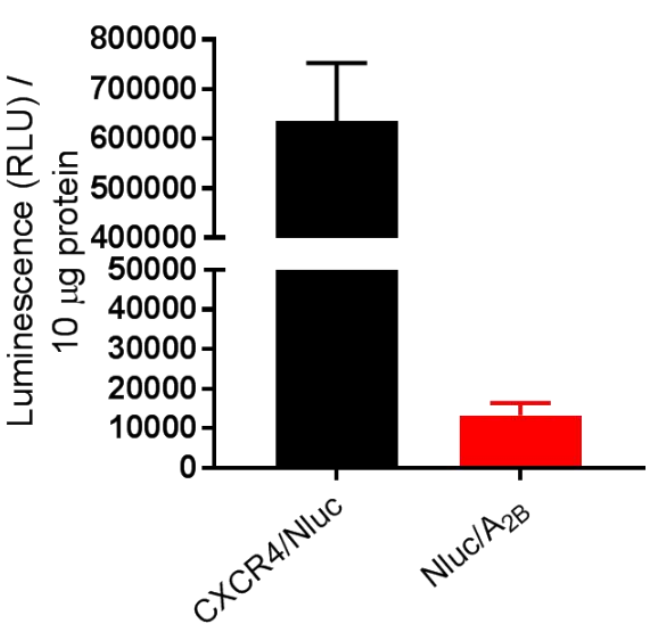

Supplementary Figure 1: (a) Gel electrophoresis of PCR products from genomic DNA extracted from edited cells; lanes A and B, PCR products generated using primers binding Nluc and outside the right homology arm (RHA) junction; lanes C-D, PCR products using primers binding within Nluc; A and C, DNA extracted from gene-edited cells; B and D, DNA extracted from wild type cells. (b) Sanger sequencing of the PCR products confirming correct editing and in-frame insertion. (c) Comparison of luminescence generated per $10 \mu \mathrm{g}$ of membrane prepared from HEK293 cells expressing gene-edited Nluc/A ${ }_{2 B}$, or CXCR4/Nluc that we have described previously ${ }^{6}$. Luminescence was measured following addition of $10 \mu \mathrm{M}$ furimazine on a PHERAstar microplate reader (BMG Labtech) with 1 second integration and 3600 gain. 
Supplementary table 1: $A D O R A 2 B$ donor plasmid repair sequence

GGTGGACGAGGATGGGACGGCCACGAGCTTGTCTTAAGGTAGAAGGCAGAGCGGGGCCGTAGG GGCAGTGGCGCGGGCGAGGTGGAGAACAGCGCTGAGCCTCGCTGGGAGGCGGCCGGAGGGGG CTGCAGCCCCCGAGGGCTCCTTGCAGTCCGGCCCCGCAGCCTGGAGACAGCTCCGGTGGTGCTG CGCTGCCCGAGACTGCTGCACGAGCGGGGACTGCGGCCTCGGCTCCCTGCCTGCCCGGCAGCCC CCCATCCAGTCGGCCTGCCCGGGGTGCGCAGGGTTAGCCTGGAGTGAGCTCGCCCCGCCCGGGG TTGCGCGGCCCTGGGGGGTCCTCTCGCGGCGGCTCCTGGGACCTGCTGGCGCCCCGGGCAGAGC CCGGCCCCATCCCAGGAGTCGCCCGGACTGGAAGGCAGTGCGAGCACTGGGACACAGCCTCCG AGCTCGAGCGTGACGGGAAGTTGGGGCAATTTGTTAGTTATCCGCCGCCACCAAGACGCGGCAC GGCGCCTGGACCGGAGGGGCCCCGCGCGGGCGCGAACTTTGGGCTCGGGCGAGTGGGTGGTGC TCCGCCCAGCCCGAGACGGGCGGGCGCGCGGGCCAATGGGTGCCGCCTCTTGGCCGCGGGGGG CCCCGACCCGTGGGTCCCGGCCACCAGCGCCCCAGCCCCGAGGCTCAGAAGCGGCAGGCGGAG GCGCGGTCCGGGCGCTATGGCCATGCCCGGCGGGTCTCACGCGGCTGCCCCTCGCCCGGCGCGC CTTCGGTAGGGGGCGCCCGCGCCCCAGCTGGCCCGGCCAAGCTTGCCACCATGAACTCCTTCTC CACAAGCGCCTTCGGTCCAGTTGCCTTCTCCCTGGGCCTGCTCCTGGTGTTGCCTGCTGCCTTCC CTGCCCCAGTCTTCACACTCGAAGATTTCGTTGGGGACTGGCGACAGACAGCCGGCTACAACCT GGACCAAGTCCTTGAACAGGGAGGTGTGTCCAGTTTGTTTCAGAATCTCGGGGTGTCCGTAACT CCGATCCAAAGGATTGTCCTGAGCGGTGAAAATGGGCTGAAGATCGACATCCATGTCATCATCC CGTATGAAGGTCTGAGCGGCGACCAAATGGGCCAGATCGAAAAAATTTTTAAGGTGGTGTACCC TGTGGATGATCATCACTTTAAGGTGATCCTGCACTATGGCACACTGGTAATCGACGGGGTTACG CCGAACATGATCGACTATTTCGGACGGCCGTATGAAGGCATCGCCGTGTTCGACGGCAAAAAGA TCACTGTAACAGGGACCCTGTGGAACGGCAACAAAATTATCGACGAGCGCCTGATCAACCCCG ACGGCTCCCTGCTGTTCCGAGTAACCATCAACGGAGTGACCGGCTGGCGGCTGTGCGAACGCAT TCTGGCGGGATCGAGCGGCGCGATCGCTGGTACCGGATCCGCGCTGCTGGAGACACAGGACGC GCTGTACGTGGCGCTGGAGCTGGTCATCGCCGCGCTTTCGGTGGCGGGCAACGTGCTGGTGTGC GCCGCGGTGGGCACGGCGAACACTCTGCAGACGCCCACCAACTACTTCCTGGTGTCCCTGGCTG CGGCCGACGTGGCCGTGGGGCTCTTCGCCATCCCCTTTGCCATCACCATCAGCCTGGGCTTCTGC ACTGACTTCTACGGCTGCCTCTTCCTCGCCTGCTTCGTGCTGGTGCTCACGCAGAGCTCCATCTT CAGCCTTCTGGCCGTGGCAGTCGACAGATACCTGGCCATCTGTGTCCCGCTCAGGTGAGGCGCT CGGCGTCGCCCGAACTCGGGGCCCCGTCGGAGCTCCGAAATGGGTCGTCTTCTCCAGGCCGGGG TTCCTCCCTCGGGGGCCCCAGACGGGCCAGGCTGGGGGCGCGCGGGGCGCTTGGAGGGCTGGT TCCCAGCCTGGCCACCCCGCAACGCTAGACCAGTGCGCCCGGGCACCCAAGACATCCCAGATGC GCGTCGCTCTAAGGAGATCTGCGTAGGGACAGCTCTAGGGGGTCCGGGGAGTGCGGTCCCCGG CGCCCGGGGAGGCGCCGTGGAAACCCCGGGGAAAGCGTCACCCCCGGGGAAAGCGTCACCCCC GTGGGCGGGTGGAGCCCGGGGCGCGGGAGTTTTGGTGATCACATCTCCACTCCTGCCACGAAGG CCGTTCCTAACACTCGCCCGCAGCGGCGGTGCAGCGGCAGTCCCGTGAGTGCTGCGGCTCCCGG AGGCCCGGGA

Plasmid containing homology arms surrounding inserted DNA was synthesised by GeneArt (Invitrogen) and contains the following features: CGC; (mutated PAM site), AAGCTTGCCACC; HindIII-Kozak, IL6 signal peptide-Nluc-linker-BamHI, GCG; No-Start (Met-Ala mutation) 
Supplementary Information

Supplementary table 2: Genomic DNA sequencing primers

\begin{tabular}{|l|l|}
\hline Primer & Sequence \\
\hline NlucFWD & CCTTGAACAGGGAGGTGTGT \\
\hline NlucRVS & CGCTTGTGGAGAAGGAGTTC \\
\hline ADORA2BGenomicRVS & CATCAGCTCCAACTGGGAAT \\
\hline
\end{tabular}

N.B. ADORA2BGenomic reverse primer designed to bind outside the repair template 